\title{
Reduction of early ventricular arrhythmia by acebutolol in patients with acute myocardial infarction ${ }^{1}$
}

\author{
GAIL G. AHUMADA, RONALD P. KARLSBERG, ALLAN S. JAFFE, \\ H. DIETER AMBOS, BURTON E. SOBEL, AND ROBERT ROBERTS
}

From the Cardiovascular Division, Washington University School of Medicine, St Louis, Missouri, USA

SUMMARY To assess the effects of intravenously administered acebutolol (1-20 mg every 4 hours for 24 hours) on cardiac rhythm and performance, we studied 72 patients with evolving myocardial infarction. Twenty-five patients were treated with acebutolol beginning 6 hours after the first increase in the level of plasma creatine kinase. Enzymatically estimated infarct size was compared with that of 25 controls matched for predicted infarct size. Observed infarct sizes were not significantly different in the 2 groups ( $37 \pm 5$ and $30 \pm 5 \mathrm{CK}$-gram equivalents, respectively). Mean heart rate, diastolic blood pressure, and cardiac output declined from control values during treatment with acebutolol, but remained within the normal range. Mean pulmonary artery pressure and pulmonary artery occlusive pressure were unchanged. In a group of 22 treated patients matched with 22 control subjects for frequency of ventricular extrasystoles, acebutolol effected a prompt reduction in frequencies of ventricular extrasystoles and repetitive arrhythmias, whereas values were not significantly changed in controls during the corresponding intervals. Accordingly, acebutolol may be a useful antiarrhythmic agent in selected patients with acute myocardial infarction without adversely altering haemodynamic stability or enzymatically estimated infarct size.

Mortality during the acute phase of myocardial infarction is increased among patients with extensive myocardial necrosis (Page et al., 1971) and among those with severe ventricular arrhythmias (Killip and Kimball, 1967). Though beta-adrenergic blockade appears to protect ischaemic myocardium (Maroko et al., 1971) and exert favourable electrophysiological effects (Harris et al., 1971) during ischaemia in experimental animals, administration of beta-adrenergic antagonists to patients with acute myocardial infarction has been tempered by the possible risk of precipitating heart failure. Acebutolol is a cardioselective beta-adrenergic antagonist with negative chronotropic effects particularly pronounced when circulating catecholamines are increased (Leary and Coleman, 1972). It alters airway resistance to a lesser extent than does propranolol (Kumana et al., 1975) and is more effective than practolol in blocking tachycardia induced by isoprenaline (Cuthbert and Collins, 1975). Furthermore, acebutolol increases exercise tolerance and reduces both angina (Biron and

'Supported in part by a National Institutes of Health Grant in Ischemic Heart Disease.

Received for publication 23 October 1978
Tremblay, 1976) and the frequency of ventricular extrasystoles in ambulatory patients with coronary artery disease (Gradman et al., 1977). To evaluate the effects of this agent on ventricular arrhythmias, haemodynamics, and enzymatically estimated infarct size in patients with evolving myocardial infarction, we studied 25 patients treated with acebutolol and 2 groups of controls.

\section{Methods}

PATIENTS STUDIED AND ACEBUTOLOL PROCEDURE

Seventy-two subjects were studied after admission to the Cardiac Care Unit of Barnes Hospital with a diagnosis of acute myocardial infarction confirmed by characteristic history, electrocardiogram, and rise in plasma creatine kinase (CK) activity. Patients who had clinically evident bronchospasm or history of asthma, hepatic failure, renal failure, or uncontrolled diabetes mellitus were excluded. Acebutolol was administered to patients selected on the basis of heart rate exceeding 75 beats per minute, blood pressure exceeding $90 / 60 \mathrm{mmHg}$, and pulmonary artery occlusive pressure less than 20 mmHg. 
Of patients in this study, 25 were treated with acebutolol. Forty-seven acted as controls, since 2 control groups were necessary. One was a group of 25 matched with the treated patients on the basis of infarct size predicted before the onset of the intervention from an analysis of early plasma CK changes. The other control group comprised 22 patients matched with 22 treated patients for the frequency of ventricular extrasystoles before the administration of acebutolol. The arrhythmiamatched groups were smaller than those matched for predicted infarct size since Holter tapes covering the appropriate time intervals were not obtained in 3 patients treated with acebutolol. The comparability of control groups with treated patients is delineated in Tables 1 and 2.

Intravenous administration of acebutolol (1 to $20 \mathrm{mg}$ every 4 hours for 24 hours) was initiated beginning 6 hours after the first rise in plasma CK activity. Dosage was adjusted to maintain heart rate between 60 and 75 beats per minute, pulmonary artery occlusive pressure below $20 \mathrm{mmHg}$, and systolic blood pressure above $90 \mathrm{mmHg}$.

\section{QUANTIFICATION OF VENTRICULAR}

ARRHY THMIA

The electrocardiograms of the 44 subjects, comprising treated patients and arrhythmia-matched controls, were continuously recorded for 15 hours after the initial increase in plasma CK activity. Holter tapes were analysed by the Argus/H computer system and checked visually (Nolle et al., 1974). Both the incidence of ventricular extrasystoles and of repetitive arrhythmias (2 or more ventricular beats in a row) were evaluated.

Twenty-two subjects not treated with acebutolol were matched with the treated group on the basis of the number of premature ventricular complexes during the first 5 hours of recording since this interval immediately preceded the time of initial administration of acebutolol to the treated patients. The frequencies of ventricular extrasystoles and repetitive arrhythmias after the onset of treatment were compared with those during corresponding intervals after the first plasma CK rise in control subjects. In addition, differences in the frequency of ventricular arrhythmias before and during treatment in patients treated with acebutolol were compared with analogous differences in the control group. Student's $t$ test was used to analyse the significance of differences between groups.

Lignocaine was administered intravenously as a $50 \mathrm{mg}$ bolus or by continuous infusion to any patient when ventricular extrasystoles exceeded 10 a minute for 3 consecutive minutes or when couplets or ventricular tachycardia occurred. During the
Table 1 Initial characteristics of treated and control patients matched for predicted infarct size

\begin{tabular}{lll}
\hline & $\begin{array}{l}\text { Acebutolol } \\
(n=25)\end{array}$ & $\begin{array}{l}\text { Controls } \\
(n=25)\end{array}$ \\
\hline Age (y) & & \\
$\quad$ Mean & 59 & 62 \\
$\quad$ Range & $36-76$ & $47-87$ \\
Sex (M:F) & $16: 9$ & $20: 5$ \\
Heart rate (beats/min) & $83 \pm 2$ & $79 \pm 3$ \\
Blood pressure (mmHg) & $138 \pm 5$ & $139 \pm 7$ \\
$\quad$ Systolic & $89 \pm 3$ & $85 \pm 4$ \\
$\quad$ Diastolic & $25 \pm 4$ & $25 \pm 4$ \\
$\quad$ Predicted infarct size & CK gram-equivalents & 25 \\
\hline
\end{tabular}

Note: Values for heart rate and blood pressure are those obtained during the one hour interval before administration of acebutolol, and during the corresponding interval in controls.

Table 2 Initial characteristics of treated and control patients matched for premature ventricular complexes

\begin{tabular}{lcc}
\hline & $\begin{array}{c}\text { Acebutolol } \\
(n=22)\end{array}$ & $\begin{array}{l}\text { Controls } \\
(n=22)\end{array}$ \\
\hline Age (y) & & \\
$\quad$ Mean & 59 & 62 \\
Range & $36-76$ & $38-80$ \\
Sex (M:F) & $14: 8$ & $15: 7$ \\
Heart rate (beats/min) & $83 \pm 2$ & $79 \pm 4$ \\
Blood pressure (mmHg) & $134 \pm 5$ & $142 \pm 7$ \\
$\quad$ Systolic & $87 \pm 4$ & $82 \pm 5$ \\
Diastolic & $2 \cdot 82 \pm 0 \cdot 43$ & $2 \cdot 76 \pm 0.43$ \\
Ventricular extrasystoles, frequency & & \\
\hline
\end{tabular}

recording intervals similar amounts of lignocaine were required in control subjects and in those receiving acebutolol $(1.67 \pm 0.25$ (SE) $\mathrm{mg} / \mathrm{min}$ and $1 \cdot 28 \pm 0 \cdot 21$, respectively).

\section{HAEMODYNAMICS}

Heart rate and blood pressure were monitored noninvasively every 15 minutes in all patients for 24 hours. Serial determinations of pulmonary artery pressure, pulmonary artery occlusive pressure (indirect left atrial pressure recorded during inflation of balloon of Swan-Ganz catheter), and cardiac output measured by thermodilution method were made with the use of a Swan-Ganz catheter in patients treated with acebutolol. Haemodynamic measurements were obtained immediately before and after each dose and $\frac{1}{2}$ hour, 1 hour, and subsequently every 2 hours after administration of the drug to assess haemodynamic response. Patients in the control groups were evaluated by invasive methods only when this was required for clinical management.

ENZYMATIC ESTIMATES OF INFARCT SIZE Enzymatic estimates of infarct size in all 25 patients treated with acebutolol were compared with 
Table 3 Effects of acebutolol on ventricular arrhythmias

\begin{tabular}{|c|c|c|c|c|}
\hline \multirow[t]{2}{*}{ Time $(h)$} & \multicolumn{2}{|c|}{ Acebutolol $(n=22)$} & \multicolumn{2}{|l|}{ Control $(n=22)$} \\
\hline & $\begin{array}{l}\text { Total ventricular } \\
\text { extrasystoles }\end{array}$ & $\begin{array}{l}\text { Repetitive } \\
\text { arrhythmias }\end{array}$ & $\begin{array}{l}\text { Total ventricular } \\
\text { extrasystoles }\end{array}$ & $\begin{array}{l}\text { Repetitive } \\
\text { arrhythmias }\end{array}$ \\
\hline $\begin{array}{c}0-5 \\
6-10 \\
11-15\end{array}$ & $\begin{array}{l}2.82 \pm 0.43 \\
2.11 \pm 0.41 \\
1.89 \pm 0.38\end{array}$ & $\begin{array}{l}0.337 \pm 0.15 \\
0.138 \pm 0.10 \\
0.113 \pm 0.06\end{array}$ & $\begin{array}{l}2.76 \pm 0.43 \\
2.81 \pm 0.44 \\
1.99 \pm 0.38\end{array}$ & $\begin{array}{l}0.499 \pm 0.17 \\
0.324 \pm 0.15 \\
0.207 \pm 0.09\end{array}$ \\
\hline
\end{tabular}

Note: The values for arrhythmias in the 6 to 10 hours in the treated group (acebutolol) were significantly less than those observed during the initial 5 hours $(P<0.025)$ but no significant difference was seen during comparable intervals in the controls.

estimates in 25 control subjects matched for projected infarct size. Blood samples for serial determinations of plasma CK activity were obtained, stored, and analysed as described previously (Roberts et al., 1975). Predicted infarct size was estimated from projected values conforming to the best fit log normal curve derived from plasma CK values during the first 6 hours after the initial rise (Shell et al., 1973). Since acebutolol was not administered until data needed for projection of the log normal curve had been obtained, estimates of predicted infarct size were not influenced by the intervention. Observed infarct size was estimated from all serial plasma $C K$ values during the first 72 hours after the initial increase or until values had returned to the normal range (Sobel et al., 1977).

\section{Results}

\section{EFFECTS OF ACEBUTOLOL ON VENTRICULAR ARRHYTHMIA}

Results of analysis of rhythm are summarised in Table 3. Because the frequency of ventricular extrasystoles is not normally distributed, statistical treatment with conventional procedures such as Student's $t$ test is not appropriate. However, when values of the frequency of ventricular extrasystoles are expressed as logarithms, the distribution of values conforms closely to a normal distribution. Accordingly, results of frequency of ventricular extrasystoles were expressed in terms of logarithmic values and were then analysed by Student's $t$ test. In patients treated with acebutolol, the natural logarithm of the total number of ventricular extrasystoles decreased from $2.82 \pm 0.43$ (mean \pm SE) during the initial 5 -hour interval to $2 \cdot 11 \pm 0 \cdot 41$ $(P<0.001)$ during the 5 hours immediately after initiation of treatment, and did not change significantly during a subsequent 5-hour recording interval $(1.89 \pm 0.38)$. Similarly, the number of complex arrhythmias decreased from $0.377 \pm 0.15$ to $0.138 \pm 0.10(P<0.05)$ during the 5 hours after the initiation of treatment and remained stable in the subsequent 5 hours $(0 \cdot 113 \pm 0.06)$. In contrast, the frequency of ventricular extra- systoles among patients in the control group was unaltered from the first to the second 5-hour interval $(2 \cdot 76 \pm 0.43$ versus $2 \cdot 81 \pm 0 \cdot 44$, respectively). Furthermore, the incidence of repetitive arrhythmias (Table 3) which was not significantly different from that of the treated patients during the first 5 hours $(P>0.35)$ did not decline significantly during the second 5 hours $(0.499 \pm 0.17$ versus $0.324 \pm 0.15$, respectively, $P>0.20$ ). Thus, administration of acebutolol effected a prompt reduction in the frequency of ventricular extrasystoles and of repetitive ventricular arrhythmias in patients with acute myocardial infarction.

\section{HAEMODYNAMICS}

The results of haemodynamic determinations are summarised in Table 4. As expected, the mean heart rate of patients treated with acebutolol decreased from $83 \pm 2$ (SE) beats per minute to $71 \pm 1(P<0.05)$ during administration of the drug. In contrast, the mean heart rate of the control group did not change during the corresponding interval ( $79 \pm 3$ compared to $81 \pm 3$ beats per minute). Mean systolic and diastolic blood pressures were similar initially in both groups and showed equivalent modest declines. Mean pulmonary artery occlusive pressure was unchanged from pretreatment values by administration of the drug but cardiac output declined from $5 \cdot 0 \pm 0.2(\mathrm{SE})$ to $4.5 \pm 0.31 / \mathrm{min}$, consistent with a decrease in heart rate.

In 2 patients treated with acebutolol the pul-

Table 4 Effects of acebutolol on haemodynamics

\begin{tabular}{lcc}
\hline & Before acebutolol & During acebutolol \\
\hline Heart rate (beats/min) & $83 \pm 2$ & $71 \pm 1$ \\
Blood pressure (mmHg) & $138 \pm 5$ & $120 \pm 4$ \\
$\quad$ Systolic & $89 \pm 3$ & $82 \pm 3$ \\
$\begin{array}{l}\text { Diastolic } \\
\text { Cardiac output (1/min) }\end{array}$ & $5 \cdot 0 \pm 0 \cdot 2$ & $4 \cdot 5 \pm 0 \cdot 3$ \\
$\begin{array}{l}\text { Mean pulmonary artery } \\
\text { pressure (mmHg) }\end{array}$ & $18 \pm 1$ & $18 \pm 1$ \\
$\begin{array}{c}\text { Mean pulmonary artery } \\
\text { occlusive pressure (mmHg) }\end{array}$ & $10 \pm 1$ & $10 \pm 1$ \\
\hline
\end{tabular}

Note: Values are expressed as mean $\pm \mathrm{SE}$ and were obtained 1 hour before acebutolol and during acebutolol treatment. 


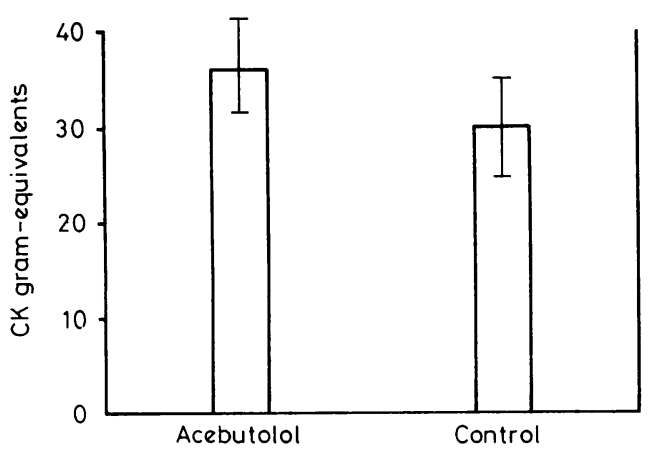

Fig. Lack of effect of acebutolol on enzymatically estimated infarct size. The bars denote mean observed infarct size \pm standard errors in treated and control groups. Mean predicted infarct sizes were equal in the two groups of patients ( $25 \pm 4$ CK gram-equivalents).

monary artery occlusive pressure rose transiently from 10 to $20 \mathrm{mmHg}$ immediately after a single dose, and returned to normal within half an hour. Neither severe bradycardia nor clinical evidence of bronchospasm was observed in any patient in the treated group. Transitory first degree heart block occurred in one patient receiving acebutolol and was the only electrophysiological complication encountered. Thus, circulatory impairment occurred in only 2 of 25 patients treated with this betaadrenergic blocking agent and in each case it was transitory.

ENZYMATIC ESTIMATES OF INFARCT SIZE

The Figure depicts effects of acebutolol on enzymatically estimated infarct size in treated patients and controls matched for predicted infarct size. Mean observed infarct size in 25 controls was not significantly different from that in patients treated with acebutolol ( $30 \pm 5 \mathrm{CK}$ gram-equivalents compared with $37 \pm 5$, respectively). Observed infarct size exceeded that predicted in each group since some patients showed secondary increases in plasma CK activity presumably indicative of extension of infarction. The frequency of this occurrence was similar in the two groups ( 8 controls and 7 patients treated with acebutolol). Thus, administration of acebutolol beginning 6 hours after the initial plasma CK rise to patients with acute myocardial infarction without pronounced haemodynamic impairment did not appear to alter enzymatically estimated infarct size or the incidence of extension of infarction.

It should be emphasised that criteria for admission to this study were such that patients with severe haemodynamic abnormalities were excluded. In fact, all the patients in this investigation were in MIRU Class I or II. Accordingly, these results cannot be extrapolated to patients with more severe disease without appropriate further investigation.

\section{Discussion}

This study was designed to determine whether a cardioselective beta-adrenergic antagonist in dosage sufficient to reduce heart rate below 75 beats per minute would reduce the frequency or severity of ventricular arrhythmia without adversely altering haemodynamics or exacerbating injury in patients with evolving myocardial infarction. Compared with results in patients untreated but matched for incidence of arrhythmias, administration of acebutolol was associated with a significant reduction in the frequency of ventricular extrasystoles and of repetitive ventricular arrhythmias.

The beneficial effects of this agent may depend on at least two mechanisms. Acebutolol may have a direct effect on the electrophysiological stability of the myocardial cell membrane, since it ameliorates arrhythmias induced by ouabain in experimental animals (Basil et al., 1974). Furthermore, acebutolol may reduce the incidence of arrhythmias by antagonising the action of circulating or locally released catecholamines (Harris et al., 1971). Plasma catecholamines are raised early in the course of infarction (Karlsberg et al., 1977) and may contribute to the genesis of arrhythmias by augmenting phase- 4 depolarisation. In addition, catecholamines augment the release of prostaglandins (Junstad and Wennmalm, 1973) and thus may indirectly contribute to the accumulation of lysophosphoglycerides which recently have been shown to reduce reversibly the transmembrane action potential and diminish $\mathrm{dV} / \mathrm{dt}$ (Corr et al., 1978) and favour re-entrant arrhythmias. Moreover, the raised plasma catecholamines often accompanying myocardial infarction may augment requirements for oxygen and substrate in jeopardised tissue when oxygen delivery is limited, thereby contributing to cellular dysfunction or damage and giving rise to zones of unidirectional block facilitating re-entrant rhythms. Beta-adrenergic blockade, by attenuating these and other effects of catecholamines on the heart, may reduce the incidence of malignant disturbances of rhythm in selected patients late after infarction (Multicentre International Study, 1975). The mechanisms involved may not necessarily be the same as those accounting for observations in the present study. Nevertheless, some late episodes of malignant arrhythmia may reflect an early response to new episodes of ischaemia, and hence protective effects of beta-adrenergic blockade may resemble 
those seen in patients with evolving infarction in the present study.

The beneficial antiarrhythmic effects of acebutolol observed in this investigation were not accompanied by untoward effects on haemodynamics, enzymatically estimated infarct size, or the incidence of extension of infarction. Though we had expected that acebutolol might decrease infarct size by reducing myocardial oxygen consumption, at least two factors might have militated against observing this result. Firstly, reduction of myocardial damage may not be a general property of beta-adrenergic antagonists, but may be a consequence of specific molecular structure of particular agents. Nayler et al. (1977) have shown that Lpropranolol reduces release of CK from hypoxic isolated perfused rabbit hearts, whereas comparable pharmacological doses of acebutolol do not and oxprenolol actually augments release. Though neither morphological studies nor analyses of tissue CK activity were performed to evaluate unequivocally the interpretation of results in the experimental animal study, the data suggest that propranolol might be more effective than acebutolol in preventing cell death. Recent reports of protective effects of dimethyl propranolol ( $\mathrm{Ku}$ and Lucchesi, 1978), an agent devoid of appreciable beta-blocking activity, are compatible with this possibility.

A second factor militating against detection of protective effects on the extent of infarction of acebutolol in the present study may relate to the timing of the intervention. Protection of myocardium during evolving infarction may be possible only with interventions implemented very soon after the onset. In most studies demonstrating protection of myocardium in experimental animals (Maroko et al., 1971, 1972a, b, c; Libby et al., 1973; Spath, et al., 1974), reduction of infarct size has been achieved with interventions initiated before or immediately after coronary artery occlusion. In contrast, clinical studies have shown no appreciable protection of myocardium with interventions initiated several hours after the onset of symptoms (Gowda et al., 1975; Gillespie et al., 1977). The method we used to predict infarct size entails a delay of 7 to 10 hours after the onset of symptoms before an intervention can be initiated if one wishes to preclude the influence of the intervention on projected infarct size. If beta-adrenergic antagonists are capable of protecting ischaemic myocardium in humans in a fashion analogous to protection in experimental animals, efficacy may depend on administration of the agent very early in the evolution of infarction. Thus, the fact that acebutolol did not reduce enzymatically estimated infarct size in the present study does not necessarily imply that beneficial effects would not be evident if the drug were administered earlier. On the other hand, the estimates of infarct size were undertaken to determine whether the electrophysiological effect of the drug could be obtained under typical clinical conditions without exacerbating apparent injury.

The results of this investigation indicate that acebutolol, a cardioselective beta-adrenergic antagonist, can be administered safely to selected patients with acute myocardial infarction without adversely altering haemodynamics or enzymatically estimated infarct size. The drug not only reduces heart rate, and presumably myocardial oxygen requirements, but also diminishes the frequency of ventricular extrasystoles and repetitive ventricular arrhythmias. Accordingly, it appears to be useful in enhancing cardiac electrical stability early after the onset of ischaemia in selected patients with coronary artery disease.

\section{References}

Basil, B., Jordan, R., Loveless, A. H., and Maxwell, D. R. (1974). A comparison of the experimental anti-arrhythmic properties of acebutolol (M \& B 17,803), propranolol and practolol. British fournal of Pharmacology, 50, 323-333.

Biron, P., and Tremblay, G. (1976). Acebutolol: basis for the prediction of effect on exercise tolerance. Clinical Pharmacology and Therapeutics, 19, 333-338.

Corr, P. B., Witkowski, F. X., Price, D. A., and Sobel, B. E. (1978). Lysophospholipids: potential precipitants of malignant arrhythmia due to ischemia (abstract). American fournal of Cardiology, 41, 366.

Cuthbert, M. F., and Ccllins, R. F. (1975). Plasma levels and $\beta$-adrenoreceptor blockade with acebutolol, practolol and propranolol in man. British fournal of Clinical Pharmacology, 2, 49-55.

Gillespie, T. A., Ambos, H. D., Sobel, B. E., and Roberts, R. (1977). Effects of dobutamine in patients with acute myocardial infarction. American fournal of Cardiology, 39, 588-594.

Gowda, K. S., Roberts, R., and Ambos, H. D. (1975). Salutary effects of external counterpulsation in patients with acute myocardial infarction (abstract). American fournal of Cardiology, 35, 140.

Gradman, A. H., Winkle, R. A., Fitzgerald, J. W., Meffin, P. J., Stoner, J., III, Bell, P. A., and Harrison, D. C. (1977). Suppression of premature ventricular contractions by acebutolol. Circulation, 55, 785-791.

Harris, A. S., Otero, H., and Bocage, A. J. (1971). The induction of arrhythmias by sympathetic activity before and after occlusion of a coronary artery in the canine heart. fournal of Electrocardiology, 4, 34-43.

Junstad, M., and Wennmalm, A. (1973). On the release of prostaglandin $E_{2}$ from the rabbit heart following infusion of noradrenaline. Acta Physiologica Scandinavica, 87, 573574.

Karlsberg, R. P., Penkoske, P., Cryer, P. E., Roberts, R., and Corr, P. B. (1977). Extent of myocardial infarction: relationship to early catecholamine release (abstract). Physiologist, 20, 50. 
Killip, T., III, and Kimball, J. T. (1967). Treatment of myocardial infarction in a coronary care unit: a two year experience with 250 patients. American fournal of Cardio$\log y, 20,457-464$.

$\mathrm{Ku}$, D. D., and Lucchesi, B. R. (1978). Effects of dimethyl propranolol (UM-272; SC-27761) on myocardial ischemic injury in the canine heart after temporary coronary artery occlusion. Circulation, 57, 541-548.

Kumana, C. R., Leighton, M., Kaye, C. M., Turner, P., and Hamer, J. (1975). Cardiac and pulmonary effects of acebutolol. Lancet, 2, 89-93.

Leary, W. P., and Coleman, A. J. (1972). Cardiovascular effects of M \& B 17803 A in man. South African Medical fournal, 46, 1202-1203.

Libby, P., Maroko, P. R., Bloor, C. M., Sobel, B. E., and Braunwald, E. (1973). Reduction of experimental myocardial infarction size by corticosteroid administration. fournal of Clinical Investigation, 52, 599-607.

Maroko, P. R., Bernstein, E. F., Libby, P., DeLaira, G. A., Covell, J. W., Ross, J., jun, and Braunwald, E. (1972a). Effects of intra-aortic balloon counterpulsation on the severity of myocardial ischemic injury following coronary artery occlusion: counterpulsation and myocardial injury. Circulation, 45, 1150-1159.

Maroko, P. R., Kjekshus, J. K., Sobel, B. E., Watanabe, T., Covell, J. W., Ross, J., jun, and Braunwald, E. (1971). Factors influencing infarct size following coronary artery occlusion. Circulation, 43, 67-82.

Maroko, P. R., Libby, P., Bloor, C. M., Sobel, B. E., and Braunwald, E. (1972b). Reduction by hyaluronidase of myocardial necrosis following coronary artery occlusion. Circulation, 46, 430-437.

Maroko, P. R., Libby, P., Sobel, B. E., Bloor, C. M., Sybers, H. D., Shell, W. E., Covell, J. W., and Braunwald, E. (1972c). Effect of glucose-insulin-potassium infusion on myocardial infarction following experimental coronary artery occlusion. Circulation, 45, 1160-1175.
Multicentre International Study (1975). Improvement in prognosis of myocardial infarction by long-term $\beta$-adrenoreceptor blockade using practolol. British Medical fournal, 3, 735-740.

Nayler, W. G., Grau, A., and Yepe, Z. (1977). $\beta$-adrenoceptor antagonists and the release of creatine phosphokinase from hypoxic heart muscle. Cardiovascular Research, 11, 344-352.

Nolle, F. M., Oliver, G. C., Kleiger, R. E., Cox, J. R., jun, Clark, K. W., and Ambos, H. D. (1974). The Argus/H system for rapid analysis of ventricular arrhythmias. In IEEE Proceedings of the Conference on Computers in Cardiology, Vol. 1, pp. 37-42.

Page, D. L., Caulfield, J. B., Kastor, J. A., DeSanctis, R. W., and Saunders, C. A. (1971). Myocardial changes associated with cardiogenic shock. New England fournal of Medicine, 285, $133-137$.

Roberts, R., Henry, P. D., and Sobel, B. E. (1975). An improved basis for enzymatic estimation of infarct size. Circulation, 52, 743-754.

Shell, W. E., Lavelle, J. F., Covell, J. W., and Sobel, B. E. (1973). Early estimation of myocardial damage in conscious dogs and patients with evolving acute myocardial infarction. Fournal of Clinical Investigation, 52, 2579-2590.

Sobel, B. E., Markham, J., and Roberts, R. (1977). Factors influencing enzymatic estimates of infarct size. American Fournal of Cardiology, 39, 130-132.

Spath, J. A., jun, Lane, D. L., and Lefer, A. M. (1974). Protective action of methylprednisolone on the myocardium during experimental myocardial ischemia in the cat. Circulation Research, 35, 44-51.

Requests for reprints to Dr Robert Roberts, Cardiac Care Unit, Washington University School of Medicine, 660 South Euclid Avenue, St Louis, Missouri 63110 , USA. 